\title{
Learning and coping strategies versus standard education in cardiac rehabilitation: a cost-utility analysis alongside a randomised controlled trial
}

Nasrin Tayyari Dehbarez ${ }^{1,3^{*}}$, Vibeke Lynggaard ${ }^{2}$, Ole May ${ }^{2}$ and Rikke Søgaard ${ }^{3,4}$

\begin{abstract}
Background: Learning and coping education strategies (LC) was implemented to enhance patient attendance in the cardiac rehabilitation programme. This study assessed the cost-utility of LC compared to standard education (standard) as part of a rehabilitation programme for patients with ischemic heart disease and heart failure.

Methods: The study was conducted alongside a randomised controlled trial with 825 patients who were allocated to LC or standard rehabilitation and followed for 5 months. The LC approach was identical to the standard approach in terms of physical training and education, but with the addition of individual interviews and weekly team evaluations by professionals. A societal cost perspective including the cost of intervention, health care, informal time and productivity loss was applied. Cost was based on a micro-costing approach for the intervention and national administrative registries for other cost categories. Quality adjusted life years (QALY) were based on SF-6D measurements at baseline, after intervention and follow-up using British preference weights. Multiple imputation was used to handle non-response on the SF-6D. Conventional cost effectiveness methodology was employed to estimate the net benefit of the LC and to illustrate cost effectiveness acceptability curves. The statistical analysis was based on means and bootstrapped standard errors.
\end{abstract}

Results: An additional cost of DKK 6,043 (95\% Cl -5,697; 17,783) and a QALY gain of $0.005(95 \% \mathrm{Cl}-0.001 ; 0.012)$ was estimated for LC. However, better utility scores in both arms were due to higher utility while receiving the intervention than better health after the intervention. The probability that LC would be cost-effective did not exceed $29 \%$ for any threshold values of willingness to pay per QALY. The alternative scenario analysis was restricted to a health care perspective and showed that the probability of cost-effectiveness increased to $62 \%$ over the threshold values.

Discussion: The LC was unlikely to be cost-effective within 5 months of follow-up from a societal perspective, but longer-term follow-up should be evaluated before a definite conclusion is drawn.

Conclusion: Future research should assess the LC strategies' long-term efficacy and cost-utility.

Trial registration: NCT01668394

Keywords: Cost-utility analysis, Rehabilitation, Patient education, Ischemic heart disease, Heart failure

\footnotetext{
* Correspondence: nastay@rm.dk

'Health Economics, Public Health and Quality Improvement, Olof Palmes Alle

15, 8200 Aarhus N, Denmark

${ }^{3}$ Department of Public Health, Aarhus University, Bartholins Allé 2, Buldg.

1260, 8000 Aarhus C, Denmark

Full list of author information is available at the end of the article
}

C Biomed Central

(C) 2015 Dehbarez et al. Open Access This article is distributed under the terms of the Creative Commons Attribution 4.0 International License (http://creativecommons.org/licenses/by/4.0/), which permits unrestricted use, distribution, and reproduction in any medium, provided you give appropriate credit to the original author(s) and the source, provide a link to the Creative Commons license, and indicate if changes were made. The Creative Commons Public Domain Dedication waiver (http://creativecommons.org/publicdomain/zero/1.0/) applies to the data made available in this article, unless otherwise stated. 


\section{Background}

Cardiac rehabilitation (CR) programmes have become an integral part of the standard of care in modern cardiology. These programmes rely on early detection of the disease process and the application of interventions to prevent disease progression [1]. However, few patients complete $\mathrm{CR}$ or succeed with lasting lifestyle improvements [2]. Despite the established value of $\mathrm{CR}$, the participation rates are disappointingly low [3], and there is a lack of visibility and recognition of the importance of $\mathrm{CR}$ by the public [4].

In the light of the favourable effects of CR, it is important to develop patient education strategies which can help patients to improve adherence to $\mathrm{CR}$ and make changes towards a healthier lifestyle $[5,6]$. To enhance patient attendance in the cardiac rehabilitation programme, a patient-education strategy called "Learning and Coping (LC)" was implemented within a randomised controlled trial (RCT) at the Regional Hospitals West Jutland in Denmark. This method was developed in Norway to address some of the challenges in patient education. Theoretical basis and study protocol of LC strategies has been published before [7, 8].

Economic evaluation of $\mathrm{CR}$ has been reported since the 1980s, and all of the studies have supported the implementation of CR [9]. The cost-effectiveness of CR is supported by evidence from 15 health economic evaluations conducted in North America and Europe [10]. Recent studies have focused on comparison among various modes of delivery of $\mathrm{CR}$, such as programmes that were outpatient, inpatient, home-based or telephone coaching programmes $[9,11]$.

The aim of this study was to evaluate whether a LC method was cost-effective compared with the standard rehabilitation of patients with ischemic heart disease (IHD) and heart failure (HF).

\section{Methods}

\section{Study design and population}

The study was conducted alongside a RCT of patient education in cardiac rehabilitation. The participants in this trial included 827 patients over 18 years who had been admitted with IHD or HF. Two patients were excluded; one because he was mistakenly randomised twice and the other because she was due for an eye operation and could not start the CR program. A total of 825 patients undergoing the CR programme, were randomised in to one of two education methods. Randomisation was computer generated and stratified by hospitals, diagnosis and gender. Use of stratified randomisation should be viewed as an insurance policy against a potential imbalance and, because it has virtually no cost, it should be routinely used in RCTs [12]. Of these patients, 413 were randomised to the LC group and 412 to the control group. All of the patients received 8 weeks (approximately 2 months) of training and education and were followed for an additional 3 months.

\section{Intervention}

In this study, LC strategies were applied and compared with the standard education in CR at three hospitals in the western part of Central Denmark Region (Table 1). Detailed components of education strategies is available in the study protocol [8].

\section{Costs}

We assessed costs from the societal perspective to estimate the long-term average costs of the routine provision of education. A micro-costing approach was used to calculate the cost of intervention. Micro costing is a method that provides crucial and detailed cost data. An accurate cost of the intervention at the micro-level is required to perform accurate economic analysis, such as cost-effectiveness or cost-benefit analyses, which gives a complete analysis of outcomes alongside the cost at which they are achievable [13].

The cost of implementing the intervention was not included in the present analysis; it should be seen as estimating the long-term average costs of implementing the intervention in routine practice. The intervention includes the cost of both formal and informal time of all persons involved.

A load factor of 1.5 was applied to the cost of health professional's formal time to account for non-productive time. Their productive time was assumed to amount to $45 \mathrm{~min}$ of an hour (load of 0.25 ) due to pauses, walking distance between locations, private time, etc. The remainder load (0.25) was considered to include vacation, sickness, participation in seminars and educational courses etc.

The valuation of formal care was based on the average gross salary of nurses and physiotherapists involved in patient education, which was provided by Regional Hospital West Jutland. Regional hospital's standard overhead rate of $21 \%$ was applied to account for capital costs.

The valuation of informal time; time spent by patients and expert patients, was undertaken using the opportunity cost method, in which the value of a person's time is

Table 1 Elements of educational strategies in cardiac rehabilitation

\begin{tabular}{ll}
\hline Learning and coping & Standard \\
\hline - Initial individual clarifying interview & \\
- 8 week group-based: & - 8 week group-based: \\
$\quad$ Physical training $1 \frac{1}{2} \mathrm{~h} \times 3 /$ week & Physical training $1 \frac{1}{2} \mathrm{~h} \times 3 /$ week \\
$\quad$ Education $1 \frac{1}{2} \mathrm{~h} /$ week & Education $1 \frac{1}{2} \mathrm{~h} /$ week \\
- Weakly team evaluation & \\
- Final individual clarifying interview & \\
\hline
\end{tabular}


reflected by his or her wage rate. The average age of expert patients was 65 years, and the valuation of their time was based on their net salary assuming they are pensioner. National average gender- and age-matched salaries were used to value the leisure time (net salary) and productive time (gross salary) [14].

The patient's time was calculated based on the recorded data on the number of training and education sessions they attended in both arms.

Transportation cost was assumed to be $20 \mathrm{~min}$ and 10 $\mathrm{km}$ each way for all patients and all contacts. The government tariff for transportation by private car for 2013 was used. Regional Hospital West Jutland paid the transportation cost of the expert patients during the intervention. To value the transportation time of the expert patient, $20 \mathrm{~min}$ in each way was assumed (Table 2).

The DREAM database, which contains information on all social benefits, was searched for events of inability to work. Productivity losses are due to sickness leave, early pension and re-schooling and, were calculated using weeks of inability to work for those who did not reach the age for pension during follow-up (67 years old). All cost estimates were adjusted for time preference and, inflated to the common price year of 2013, using the consumer price index where relevant (DKK $100 \approx \mathrm{GBP}$ $10 \approx$ USD 18).

Data on primary health care use (number of visits and the related activity-based tariffs) were extracted from the National Health insurance service register [15], and the data on the use of secondary health care services (number of services and national average Diagnosticrelated grouping (DRG) tariffs) were extracted from the National Patient Registry (NPR) [16]. The data for prescribed medicine were extracted from the national prescription registry [17]. The DRG is revised every year and is based on the average use of resources in each group. The NPR includes administrative information, diagnoses, diagnostic and treatment procedures using several international classification systems, including the International Classification of Disease and Related Health Problems $10^{\text {th }}$ revision [18].

\section{Outcome parameter}

The outcome parameter in the study was health-related quality of life, as defined by the SF-6D. The SF-6D scores were preference-weighted using British weights [19]. QALY was estimated as the area under the health utility curve over time using linear interpolation between observations [20].

\section{Imputation}

The data suffered missing values on the SF-6D scores, while complete data on cost were obtained from administrative national registers with full coverage and thus were not subjected to imputation. To avoid the loss of information on the outcome parameters, the missing values were replaced using multiple imputation, which is generally used to address data missing at random [21].

Imputation was produced using a chained equation approach [22] because the non-response was of a nonmonotonic character (e.g., a non-response at baseline could return and become a response after intervention or follow-up). Furthermore, sensitivity analysis was conducted for the alternative analytical choice of carrying the baseline observation to impute missing values after the intervention and carry the after intervention observation to impute missing values on the 3-month follow-ups.

Table 2 Item costs used for estimating the costs of patient education in cardiac rehabilitation programme

\begin{tabular}{|c|c|c|}
\hline Resources & Cost & Source \\
\hline \multicolumn{3}{|l|}{ Time cost of formal care } \\
\hline Nurse (DKK /hour) & 197 & Regional Hospital West Jutland \\
\hline Physiotherapist (DKK/hour) & 160 & Regional Hospital West Jutland \\
\hline Load-factor for personnel time (weight) ${ }^{a}$ & 1.5 & Researcher assumption \\
\hline Expert patient, 65 years old, net salary (DKK/hour) & 108 & Statistics Denmark \\
\hline Capital cost & $21 \%$ & Hospital standard rate \\
\hline \multicolumn{3}{|l|}{ Time cost of informal time (examples) ${ }^{b}$} \\
\hline Male, 60-64years old, gross salary (DKK/hour) & 164 & Statistics Denmark \\
\hline Male, 60-64years old, net salary (DKK/hour) & 144 & Statistics Denmark \\
\hline Female, 60-64years old, gross salary (DKK/hour) & 134 & Statistics Denmark \\
\hline Female, 60-64years old, net salary (DKK/hour) & 111 & Statistics Denmark \\
\hline Transportation cost, expert patients (DKK/way) & 49 & Regional Hospital West Jutland \\
\hline Transportation cost, patients (DKK/kilometres) & 3.82 & Danish Government \\
\hline
\end{tabular}

${ }^{\mathrm{a}} \mathrm{A}$ load-factor was applied to account for non-productive time of therapist and other absence from work

${ }^{\mathrm{b}}$ Complete set of age- and gender- specific national average salaries was used (available at http://statistikbanken.dk) 
The data on patient attendance at education sessions were not registered in the first six months of the study. In this case, missing data was completely random and did not depend on observed or unobserved values [23], and to avoid loss of information, the missing values were imputed by a mean within the randomisation groups.

\section{Statistical methods}

Baseline characteristics were summarised using conventional summary statistics. The comparative analysis of the individual parameters and of the net benefit was based on the means with bootstrapped standard error [24]. Non-parametric bootstrapping with 10,000 replications was applied due to the skewed nature of both resource use and cost, and a general significance level of 0.05 was used.

The analytical strategy was implemented for two scenarios: cases with a complete response of the outcome parameter and, an imputed dataset in which missing values of the outcome parameter were imputed. Although both scenarios are shown, the latter was considered the main analysis.

Economic evaluation is subject to uncertainty not only because of sample variation but also because of assumptions made and generalisability issues [25]. We therefore conducted an analysis of alternative scenarios to test the methodological uncertainty of the imputation procedure and costs. The impact of the alternative scenarios was also illustrated using cost-effectiveness acceptability curves. All analyses were conducted in STATA version 13.

\section{Cost-utility evaluation}

We estimated the net benefit using a range of hypothetical threshold values for decision-makers' willingness to pay for a QALY (from DKK 0 to DKK 500000) and presented the incremental cost and incremental effects visually in a so-called cost-effectiveness acceptability curve $(\mathrm{CEAC})$. The CEAC was used to illustrate the probability of the intervention being cost-effective for the range of threshold values for willingness to pay for a
QALY [26, 27]. These curves illustrate the probability that an intervention (LC) is cost effective compared with the control (standard) for a continuum of hypothetical threshold values of willingness to pay for a QALY.

\section{Ethics}

Approval from Central Denmark Region ethics committee is obtained (journal number 20100230) and all participants provided written informed consent.

\section{Results}

A total of 825 patients were included in the study. A summary of the patients' baseline characteristics is presented in table 3, and no significant baseline differences in age, gender and diagnosis between the groups were found. Patients in the LC group participated in significantly more training and education sessions than did participants in the control group.

\section{Intervention cost}

Table 4 details the costs of the intervention using a micro-costing approach based on an average number of 10 patients in each course. Because there was no registration of the exact duration of each session, the planned $1.5 \mathrm{~h}$ of education and training and $1 \mathrm{~h}$ for the interview and weekly team evaluation were applied. The provision of LC in $\mathrm{CR}$ was estimated to incur an additional intervention cost of DKK 2072 compared with the standard method for one patient.

\section{Resource utilisation and cost}

Tables 5 and 6, show the mean resource utilisation and cost, respectively. Patients in the LC arm used more health resources in primary healthcare, medicine prescription and outpatient visits, but only the difference in outpatient visits was statistically significant $(p=0.002)$.

The number of sick-leave weeks due to disability pension was higher in the LC arm, and it was higher in the standard arm due to re-schooling and sick leave. However, these differences were not statistically significant.

Table 3 Population characteristics

\begin{tabular}{|c|c|c|}
\hline & Learning and coping $(n=413)$ & Standard $(n=412)$ \\
\hline Age at randomisation, mean (range) & $63(33-92)$ & $63(27-89)$ \\
\hline Male gender, n (\%) & $313(76)$ & $312(76)$ \\
\hline \multicolumn{3}{|l|}{ Diagnosis } \\
\hline Ischemic heart disease, n (\%) & $326(79)$ & $323(78)$ \\
\hline Heart failure, n (\%) & $87(21)$ & $89(22)$ \\
\hline \multicolumn{3}{|l|}{ Adherence to programme sessions } \\
\hline Physical training, mean (range)* & $19.61(1-24)$ & $18.48(1-24)$ \\
\hline Education, mean (range)* & $6.46(0-9)$ & $5.97(0-9)$ \\
\hline
\end{tabular}

The asterisks indicate statistically significant differences 
Table 4 Cost of cardiac rehabilitation programme (DKK)

\begin{tabular}{|c|c|c|c|c|}
\hline & \multicolumn{2}{|c|}{ Learning and coping } & \multicolumn{2}{|l|}{ Standard } \\
\hline & Number of units & $\overline{\text { Total cost }}$ & Number of units & Total cost \\
\hline \multicolumn{5}{|l|}{ Nurse } \\
\hline Training sessions (hours) & 36 & 7092 & 36 & 7092 \\
\hline Education sessions (hours) & 8 & 1576 & 8 & 1576 \\
\hline Interviews (hours) & 10 & 1970 & 0 & 0 \\
\hline Weekly team evaluation (hours) & 8 & 1576 & 0 & 0 \\
\hline Load for unproductive time & 31 & 6107 & 22 & 4334 \\
\hline Total & 93 & 18,321 & 66 & 13,002 \\
\hline \multicolumn{5}{|l|}{ Physiotherapist } \\
\hline Training sessions (hours) & 36 & 5760 & 36 & 5760 \\
\hline Education sessions (hours) & 4 & 640 & 4 & 640 \\
\hline Interviews (hours) & 10 & 1600 & 0 & 0 \\
\hline Weekly team evaluation (hours) & 8 & 1280 & 0 & 0 \\
\hline Load for unproductive time & 29 & 4640 & 20 & 3200 \\
\hline Total & 87 & 13,920 & 60 & 9600 \\
\hline \multicolumn{5}{|l|}{ Expert patient } \\
\hline Training sessions (hours) & 12 & 1296 & 0 & 0 \\
\hline Education sessions (hours) & 12 & 1296 & 0 & 0 \\
\hline Weekly team evaluation (hours) & 8 & 864 & 0 & 0 \\
\hline Transportation time (hours) & 16 & 1728 & 0 & 0 \\
\hline Transportation ${ }^{a}$ & Not applicable & 2304 & 0 & 0 \\
\hline Total & 48 & 7488 & 0 & 0 \\
\hline Overhead & & 8343 & & 4746 \\
\hline Total cost for 10 patients & & 48,072 & & 27,348 \\
\hline Average cost per patient & & 4807 & & 2735 \\
\hline
\end{tabular}

${ }^{a}$ Transportation cost of expert patients was paid by hospitals. The average for one course was calculated

Patient time was statistically significantly higher in the LC arm due to participation in clarifying interviews at the beginning and the end of the intervention in addition to more adherence to training and education sessions.

The total societal costs of the intervention and caring for a patient with IHD or HF were estimated to average DKK 108,388 and DKK 102,345 in the LC and standard arms, respectively.

\section{Health outcomes}

The analysis that was based on the completed response on out-come parameter at all steps consisted of $58.19 \%$ cases in the LC arm and $54.42 \%$ in the control arm.

Due to reduction in the number of respondents after the intervention and follow-up, multiple imputation was used. A non-response analysis was conducted for age, gender, primary health care cost, secondary health care cost, medicine cost, production loss cost and the number of attended education and training sessions for missing values in the effect parameters. Statistical significance was observed for all variables except age, gender, primary health care cost and intervention cost. The identified predictors of non-responses were used in the imputation procedure on which the main analysis was based. The extent and impact of imputation is shown in table 7. The imputed values for the SF-6D scores were generally lower than the observed values, which indicates that responders were generally better off than non-responders. However, better utility scores in both arms were due to higher utility while receiving the intervention than better health after the intervention. No statistically significant differences in SF-6D scores were observed between the groups.

\section{Cost-utility}

Because the intervention did not seem to be cost saving, the potential for cost-effectiveness was limited. Figure 1 shows the probability of the intervention being costeffective on a continuum of hypothetical threshold values for decision-makers willingness to pay for an additional QALY. The curve improves slightly for increasing 
Table 5 Resource use during 5 months of follow-up ${ }^{a}$

\begin{tabular}{|c|c|c|c|}
\hline & $\begin{array}{l}\text { Learning andcoping } \\
(n=413)\end{array}$ & $\begin{array}{l}\text { Standard } \\
(n=412)\end{array}$ & $\begin{array}{l}\text { Difference } \\
\text { (Cl } 95 \%)\end{array}$ \\
\hline \multicolumn{4}{|l|}{ Primary health care (contacts) } \\
\hline General practice & $13.58(0.56)$ & $12.93(0.58)$ & $0.65(-0.94 ; 2.23)$ \\
\hline Medical specialist & $0.93(0.10)$ & $0.90(0.11)$ & $0.03(-0.26 ; 0.32)$ \\
\hline Physiotherapist & $1.98(0.39)$ & $1.84(0.35)$ & $0.14(-0.89 ; 1.16)$ \\
\hline Dentist & $1.66(0.10)$ & $1.49(0.09)$ & $0.17(-0.09 ; 0.44)$ \\
\hline Other & $0.09(0.03)$ & $0.09(0.03)$ & $0.005(-0.07 ; 0.08)$ \\
\hline Prescribed medicine & $15.46(0.59)$ & $14.58(0.68)$ & $0.89(-0.87 ; 2.65)$ \\
\hline \multicolumn{4}{|l|}{ Secondary health care } \\
\hline Outpatient visits* & $26.61(0.43)$ & $24.51(0.50)$ & $2.10(0.80 ; 3.41)$ \\
\hline Hospital bed days & $1.54(0.34)$ & $1.38(0.29)$ & $0.17(-0.71 ; 1.05)$ \\
\hline Hospital admissions ${ }^{b}$ & $0.49(0.06)$ & $0.57(0.08)$ & $-0.09(-0.28 ; 0.11)$ \\
\hline Sick-leave weeks & $4.69(0.44)$ & $4.54(0.44)$ & $0.15(-1.07 ; 1.37)$ \\
\hline Re-schooling ${ }^{c}$ & $0.02(0.02)$ & $0.05(0.05)$ & $-3.03(-0.15 ; 0.08)$ \\
\hline Disability pension & $2.12(0.31)$ & $1.60(0.28)$ & $0.52(-0.30 ; 1.33)$ \\
\hline Sick Weeks & $2.13(0.31)$ & $2.33(0.31)$ & $-0.2(-1.06 ; 0.66)$ \\
\hline \multicolumn{4}{|l|}{ Informal time of patients } \\
\hline Patient time in course (hours) ${ }^{*}$ & $40.92(0.64)$ & $36.68(0.76)$ & $4.23(2.28 ; 6.18)$ \\
\hline Patient time in transportation (hours) & $18.59(0.28)$ & $16.30(0.34)$ & $2.28(1.42 ; 3.14)$ \\
\hline Patient transportation (kilometre) & $557.71(8,68)$ & $489.13(10.28)$ & $68.58(42.39 ; 94.77)$ \\
\hline
\end{tabular}

avalues are mean (SE), unless otherwise stated

${ }^{\mathrm{b}}$ Hospital admissions account for average number of admissions to the different hospital wards

${ }^{c}$ Re-schooling refer to a situation in which patient is learning new skills because he/she is not able to stay in the current job

The asterisks indicate statistically significant differences

threshold values of willingness to pay due to a slight increase in QALY gained by LC. The probability for cost-effectiveness did not exceed $29 \%$ for the imputation-based analysis and $51 \%$ for complete-response based analysis over the range of threshold values.

Figure 2 shows how cost-effectiveness changes for several scenarios regarding imputation and various cost alternatives. Examining the cost from the health care provider's perspective increased the probability of cost-effectiveness to $62 \%$ over threshold values. Cost-effectiveness was not markedly different across various cost scenarios, including therapists with lower salaries (DKK 150 per hour for a nurse and DKK 120 per hour for a physiotherapist), excluding the load factor and using a maximum number of 12 patients per session. Excluding patients time resulted in the probability of cost-effectiveness reaching $36 \%$ over the threshold values.

Because the discharge date from the hospital for some patients occurred after the follow-up period, we performed a sensitivity analysis that excluded these admissions from the study. This sensitivity analysis resulted in the probability of cost-effectiveness reaching $30 \%$ over the threshold values.

\section{Discussion}

The present economic evaluation examined the costutility of patient education in CR and was designed to assist health care providers in determining which education strategy should be provided. The main finding was that LC is unlikely to be cost-effective because it led to a higher average usage of all care categories except inpatient care, and the additional QALY generated was not statistically significant. The LC education was also associated with higher costs compared with standard education. This higher cost was primarily driven by higher outpatient costs, productivity loss costs and patient time costs.

The lower rate of hospital admissions in the LC arm could be due to more effective education, which may have led to seeking medical interventions earlier in the disease process. Because we analysed health care utilisation during a limited period of 5 months, the longer-term health care utilisation and costs are unclear.

To the best of our knowledge, this is the first report on cost-utility of various patient education strategies in CR of patients with IHD or HF in Denmark. In a review of patient education in the management of coronary heart disease, James P.R. Brown stated that five studies reported healthcare utilisation and costs, but no study 
Table 6 Mean cost (SE) during 5 months of follow-up (DKK)

\begin{tabular}{|c|c|c|c|}
\hline & $\begin{array}{l}\text { Learning and coping } \\
(n=413)\end{array}$ & $\begin{array}{l}\text { Standard } \\
(n=412)\end{array}$ & $\begin{array}{l}\text { Difference } \\
\text { (Cl } 95 \%)\end{array}$ \\
\hline Intervention $^{\mathrm{a}}$ & 4807 & 2735 & 2072 \\
\hline \multicolumn{4}{|l|}{ Primary health care } \\
\hline General practice & $1361(6042)$ & $1314(66.33)$ & $47(-128.50 ; 221.89)$ \\
\hline Medical specialist & $252(33.16)$ & $234(35.65)$ & $17(-77.51 ; 112.57)$ \\
\hline Physiotherapist & $120(28.35)$ & $112(26.01)$ & $8(-66.59 ; 82.49)$ \\
\hline Dentist & $186(14.38)$ & $160(10.30)$ & $26(-8.67 ; 60.52)$ \\
\hline Other & $28(9.47)$ & $31(12.60)$ & $-4(-34.93 ; 26.10)$ \\
\hline Total & $1947(81.49)$ & $1853(86.85)$ & $94(-140.80 ; 329.06)$ \\
\hline Prescribed medicine & $2064(95.18)$ & $2022(108.45)$ & $42(-239.60 ; 323.62)$ \\
\hline \multicolumn{4}{|l|}{ Secondary health care } \\
\hline Outpatient visits & $44,050(800.01)$ & $41,513(1018.42)$ & $2537(-16.31 ; 5090.90)$ \\
\hline Hospital admissions & $17,644(3056.81)$ & $19,250(3027.52)$ & $-1608(-10091.22 ; 6875.10)$ \\
\hline Total & $61,692(3171.31)$ & $60,763(3172.60)$ & $929(-7863.18 ; 9721.64)$ \\
\hline \multicolumn{4}{|l|}{ Productivity loss } \\
\hline Re-schooling & $116(114.41)$ & $242(237.63)$ & $-126(-679.55 ; 428.17)$ \\
\hline Disability pension & $13,392(2030.54)$ & $10,336(1847.17)$ & $3056(-2290.51 ; 8402.31)$ \\
\hline Sick Weeks & $14,450(2120.91)$ & $15,660(2144.589)$ & $-1210(-7203.09 ; 4783.19)$ \\
\hline Total & $27,958(2738.37)$ & $26,238(2708.10)$ & $1720(-5885.65 ; 9326.14)$ \\
\hline \multicolumn{4}{|l|}{ Informal time } \\
\hline Patient time in course & $5354(95.36)$ & $4752(105.19)$ & $602(321.84 ; 881.86)$ \\
\hline Patient time in transportation & $2433(42.35)$ & $2112(47.08)$ & $321(196.77 ; 444.68)$ \\
\hline Total & 7788 (134.64) & $6864(153.19)$ & $923(523.95 ; 1322.82)$ \\
\hline Patient transportation & $2130(32.34)$ & $1868(38.88)$ & $262(162.93 ; 361.03)$ \\
\hline Total costs & $108,388(4245.75)$ & $102,345(4199.11)$ & $6043(-5697.02 ; 17783.36)$ \\
\hline
\end{tabular}

${ }^{a}$ Measuring confidence interval for intervention is not applicable

Table 7 QALY during 5 months of follow-up

\begin{tabular}{|c|c|c|c|c|c|c|c|}
\hline & \multicolumn{3}{|c|}{ Learning and coping } & \multicolumn{3}{|c|}{ Standard } & \multirow{2}{*}{$\begin{array}{l}\text { Difference } \\
\text { (Cl } 95 \%)\end{array}$} \\
\hline & $n$ & Mean & (SE) & $n$ & Mean & (SE) & \\
\hline \multicolumn{8}{|l|}{ Complete response-based analysis } \\
\hline \multicolumn{8}{|l|}{ SF-6D } \\
\hline Baseline & 238 & 0.739 & 0.008 & 223 & 0.723 & 0.008 & $0.016(-0.006 ; 0.039)$ \\
\hline After intervention (2 months) & 238 & 0.798 & 0.007 & 223 & 0.780 & 0.008 & $0.018(-0.003 ; 0.040)$ \\
\hline After follow-up (5 months) & 238 & 0.794 & 0.008 & 223 & 0.792 & 0.008 & $0.002(-0.020 ; 0.025)$ \\
\hline QALY & 238 & 0.327 & 0.003 & 223 & 0.322 & 0.003 & $0.005(-0.003 ; 0.014)$ \\
\hline \multicolumn{8}{|l|}{ Multiple imputation-based analysis } \\
\hline \multicolumn{8}{|l|}{ SF-6D } \\
\hline Baseline & 413 & 0.720 & 0.006 & 412 & 0.705 & 0.006 & $0.014(-0.003 ; 0.032)$ \\
\hline After intervention ( 2 months) & 413 & 0.771 & 0.006 & 412 & 0.754 & 0.006 & $0.016(-0.001 ; 0.034)$ \\
\hline After follow-up (5 months) & 413 & 0.788 & 0.006 & 412 & 0.782 & 0.006 & $0.006(-0.011 ; 0.023)$ \\
\hline QALY & 413 & 0.319 & 0.002 & 412 & 0.314 & 0.002 & $0.005(-0.001 ; 0.012)$ \\
\hline
\end{tabular}




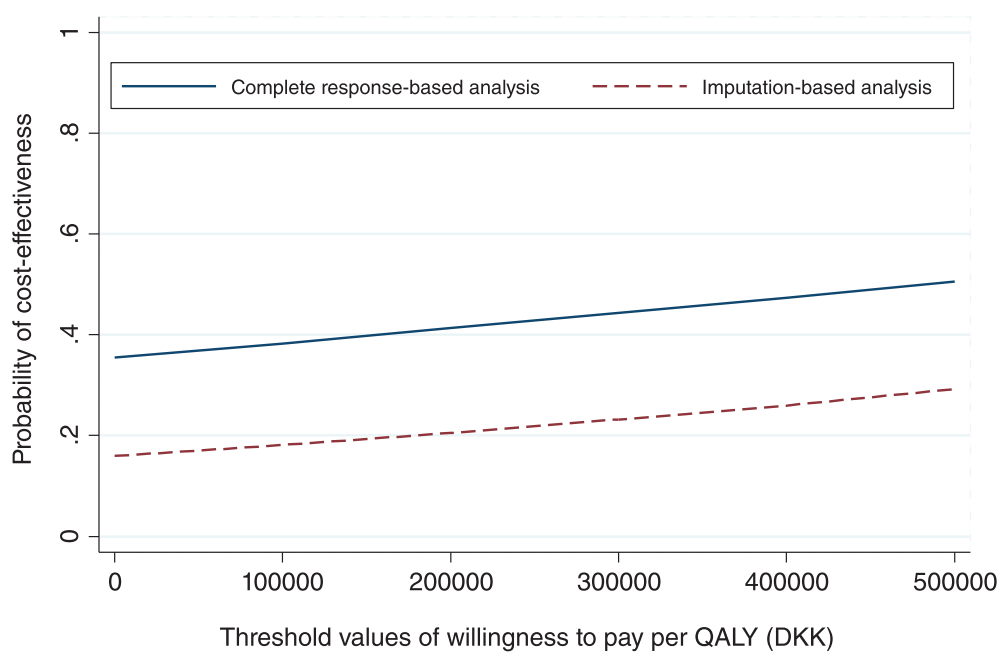

Fig. 1 Cost-effectiveness acceptability curve: main analysis

reported on cost-effectiveness. Reflecting on the various education modalities and intensities of the intervention, the reported cost of provision per patient varied from 49 to $453 \mathrm{lb}$. He found no strong evidence that education reduced all-cause mortality, cardiac morbidity, revascularisation or hospitalisation compared with the control. However, there is some evidence that patient education may be cost saving compared with usual care because of a reduction in downstream healthcare utilisation [28].

In a systematic review on patient education strategies for hospitalised cardiovascular patients, Yvonne CommodoreMensah stated that it is unclear which educational intervention elements or strategies are most effective for educating hospitalised cardiovascular patients and their families. Her review showed that there are various patient education strategies that can be implemented for hospitalised cardiovascular patients and families; however, interventions need to be feasible as well as cost-effective [29].
In a recent study in Australia, Sangster et al. compared the cost-effectiveness of a telephone-delivered Healthy Weight intervention to a telephone-delivered Physical Activity intervention and reported an average gain of 0.007 additional QALY and a difference of $\$ 852$ in cost, both in favor of the Healthy Weight intervention.

We did not find a significant improvement in health status as assessed with the SF-6D in both the LC and standard groups. Additional studies have also indicated that if the follow-up period is 6 months or less, no significant improvement in quality of life or functional status of patients with coronary heart disease is found [30]. A systematic review and meta-analysis performed by Rod S. Taylor on exercise-based rehabilitation for patients with coronary heart disease identified 12 trials that assessed health-related quality of life using a range of outcome measures. Although all trials demonstrated an improvement in quality of life with cardiac rehabilitation, an

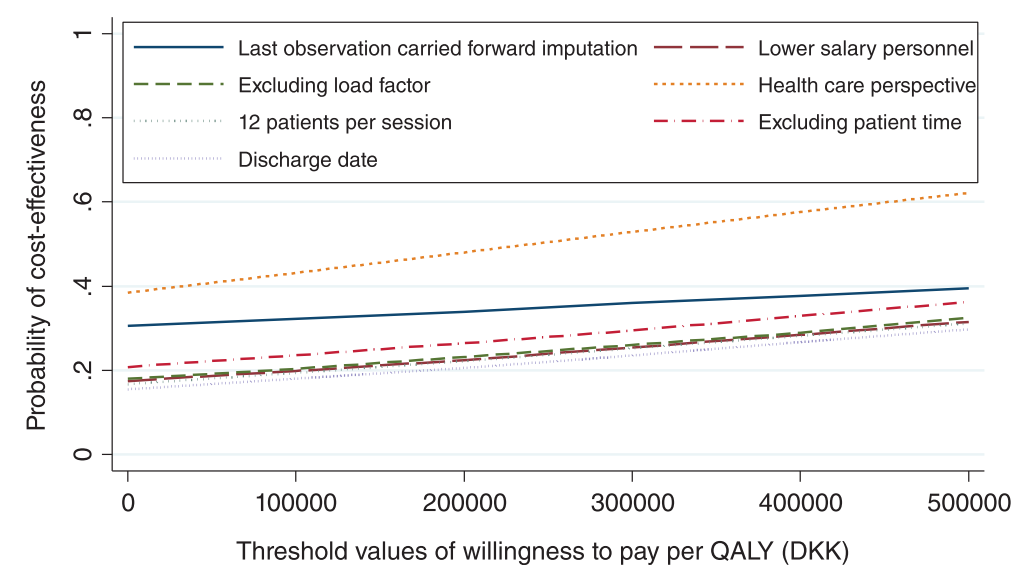

Fig. 2 Cost-effectiveness acceptability curve: sensitivity analysis 
improvement was also reported consistently in control patients [31].

\section{Strengths and weaknesses of the study}

Complete data on the costs derived from the national registries was one of the strong aspects of this study [15-17]. Additionally, using the SF-6D is suitable to measure health-related quality of life [32]. Another strength of the study was that rather than ignoring nonresponders, we chose to use a multiple imputation strategy. The validity of the imputation procedure was based on the assumption that the data were missing at random.

\section{Conclusion}

In this study, we demonstrated that there were no significant differences in either costs or outcomes between LC and standard education methods from a societal perspective during 5 months follow-up. We concluded that LC was not a cost-effective intervention in the short term; however, analysing a longer period of follow-up seems necessary because a higher cost of outpatient care in LC may result in future cost saving. Therefore, it could be suggested that health problems may be identified at an earlier stage, thereby resulting in better health outcomes.

\section{Competing interests}

The authors declare that they have no competing interests.

\section{Authors' contribution}

NTD designed the cost analysis, undertook all economic analyses and drafted the manuscript. OM and VL led the RCT and provided details of the intervention, results of the programme adherence and other information regarding RCT. RS supervised the economic study, assisted in statistical analysis and interpretation of data. All authors participated in the revision of the manuscript and approved the final version.

\section{Authors' information}

Not applicable.

\section{Availability of data and materials}

Not applicable.

\section{Acknowledgements}

The authors would like to thank the nurses, physiotherapists and expert patients, as well as the project coordinators for their contribution to patient recruitment, intervention and data collection.

The Danish Ministry of Health funded the RCT in 2010.

\section{Funding}

The Danish Ministry of Health, the Health Research Fund of Central Denmark Region andthe Danish foundation 'TrygFonden' funded the RCT.

\section{Author details}

${ }^{1}$ Health Economics, Public Health and Quality Improvement, Olof Palmes Alle 15, 8200 Aarhus N, Denmark. ${ }^{2}$ Cardiovascular Research Unit, Regional Hospital West Jutland, 7400 Herning, Denmark. ${ }^{3}$ Department of Public Health, Aarhus University, Bartholins Allé 2, Buldg. 1260, 8000 Aarhus C, Denmark. ${ }^{4}$ Department of Clinical Medicine, Aarhus University, Bartholins Allé 2, Buldg. 1260, 8000 Aarhus C, Denmark.

Received: 18 September 2014 Accepted: 18 September 2015

Published online: 28 September 2015

\section{References}

1. Mampuya WM. Cardiac rehabilitation past, present and future: an overview. Cardiovasc Diagn Ther. 2012;2:38-49. doi:10.3978/j.issn.2223-3652.2012.01.02.

2. Reimer SW, Simoons ML, Boersma E, Gitt AK. Cardiovascular Diseases in Europe In:. European Society of Cardiology. 2006. http://www.escardio.org/ static file/Escardio/EORP/about/EHS-CVD-report-2006.pdf/ cardiovasular disease in Europe. Accessed 1 Aug 2015

3. Jackson L, Leclerc J, Erskine Y, Linden W. Getting the most out of cardiac rehabilitation: a review of referral and adherence predictors. HeartBMJ. 2005:91:10-4. doi:10.1136/hrt.2004.045559.

4. Leo AS, Franklin BA, Costa F, Balady GJ, Berra KA, Stewart KJ, Thompson D, Williams MA, Lauer MS. Cardiac Rehabilitation and Secondary Prevention of coronary heart disease. American Heart Association, 2005; doi: 10.1161/ 01.CIR.0000151788.08740.5C

5. Grace SL, Abbey SE, Shnek ZM, Irvine J, Franche RL, Stewart DE. Cardiac rehabilitation I: review of psychosocial factors. Gen Hosp Psychiatry. 2002;24(3):121-6.

6. Goulding L, Furze G, Birks Y. Randomized controlled trials of interventions to change maladaptive illness beliefs in people with coronary heart disease: systematic review. J Adv Nurs. 2010;66(5):946-61.

7. Wittrup I. Learning and Coping. Patient Education on the Patients' Premises. Central Denmark Region: Public Health and Quality Improvement. 2011. http://www.cfk.rm.dk. Accessed 1 Aug 2015.

8. Lynggaard V, May O, Beauchamp A, Nielsen CV, Wittrup I. LC-REHAB: randomized trial assessing the effect of a new patient education method -learning and coping strategies- in cardiac rehabilitation. BMC Cardiovasc Disord. 2014;14:186.

9. Wong WP, Fenf J, Pwee kH, Lim J. A systematic review of economic evaluation of cardiac rehabilitation. BMC Health Serv Res. 2012;12:243.

10. Bethel JNH, Lewin JPR, Dalal HM. Cardiac rehabilitation: it works so why isn't it done (editorial). Br J Gen Pract. 2008;58:677-9. doi:10.3399/bjgp08X342219.

11. Sangster J, Church J, Haas M, Furber S, Bauman A. A Comparison of the Cost-effectiveness of Two Pedometer-based Telephone Coaching Programes for People with Cardiac Disease. Hearth, lung and Circulation. 2015;24:471-9.

12. Stanely K. Design of Randomised Controlled Trials. American Hearth Association 2007; doi: 10.1161/CIRCULATIONAHA.105.594945

13. Charles JM, Edwards RT, Bywater T. Micro-Costing in Public Health Economics: Steps Towards a Standardized Framework, Using the Incredible Years Toddler Parenting Program as a Worked Example. Prev Sci. 2013:14:377-89. doi:10.1007/s11121-012-0.

14. Statistics Denmark. Gross and Disposable income by region, gender and age range. 2014. http://www.statistikbanken.dk. Accessed 30 Apr 2014

15. Andersen JS, Olivarius NF, Krasnik A. The Danish National Health Service Registry. Scand J Public Health. 2011;39:34-7. doi:10.1177/1403494810394718.

16. Lynge E, Sandegaard JL, Rebolj M. The Danish National Patient Register. Scand J Public Health. 2011:39:30-3. doi:10.1177/1403494811401482.

17. Kildemoes HW, Sørensen HT, Hallas J. The Danish National Prescription Registry. Scand J Public Health. 2011;39:38-41. doi:10.1177/1403494810394717.

18. Løkke A, Hilberg O, Tønnesen P, Ibsen R, Kjellberg J, Jennum P. Direct and indirect economic and health consequences of COPD in Denmark: a national register-based study: 1998-2010. BMJ. 2014;4:e004069. doi:10.1136/bmjopen-2.

19. Brazier J, Roberts J, Deverill M. The estimation of preference-based measure of health from the SF-36. J Health Econ. 2001;21:271-92.

20. Manca A, Hawkins N, Sculpher MJ. Estimating mean QALYs in trial-based cost-effectiveness analysis: the importance of controlling for baseline utility. Health Econ. 2005;14:487-96.

21. Sterne JA, White IR, Carlin JB, Spratt M, Royston P, Kenward MJ, et al. Multiple imputation for missing data in epidemiological and clinical research: potentials and pitfalls. BMJ. 2009; doi: http://dx.doi.org/10.1136/ bmj.b2393.

22. White IR, Royston P, Wood AM. Multiple imputation using chained equations: Issues and guidance for practise. Stat Med. 2011;30:377-99.

23. Roysten $P$, White IR. Multiple imputation by chained equations (MICE): Implementation in STATA. J Stat Softw. 2011;45:4.

24. Efron B, Tibshirani R. Bootstrap methods for standard errors, confidence intervals and other measures of statistical accuracy. Stat Sci. 1986;1:54-77.

25. Drummond M, Sculpher M. Common Methodological Flaws in Economic Evaluation. Med Care. 2005;43:117-14.

26. Hoch JS, Briggs AH, William AR. Something old, something new, something borrowed, something blue: a framework for the marriage of health 
econometrics and cost-effectiveness analysis. Health Econ. 2002;11:415-30. doi:10.1002/hec.678.

27. Stinnett AA, Mullahy j. Net benefits: a new framework for the analysis of uncertainty in cost-effectiveness analysis. Med Decis Mak. 1998;18:68-80.

28. Brown JP, Clarck AM, Dalal H, Welch K, Taylor RS. Patient education in the management of coronary heart disease. The Cochrane Library.

2011;7(12):CD008895. doi:10.1002/14651858.CD008895. pub2.

29. Commodore-Mensah Y, Himmelfarb CR. Patient education strategies for hospitalized cardiovascular patients, A systematic review. J cardiovasc Nurse. 2011;27(2):154-74. doi:10.1097/JCN.0b013e318239f60f.

30. Murchie P, Campbell NC, Ritchie LD, Deans HG, Thain J. Effects of secondary prevention clinics on health status in patients with coronary heart disease: 4-year follow-up of a randomized trial in primary care. Fam Pract. 2004;21(5):567-74. doi:10.1093/fampra/cmh514.

31. Taylor RS, Brown A, Ebrahim S, Jolliffe J, Noorani H, Rees K, et al. Exercisebased rehabilitation for patient with coronary heart disease: systematic review and and meta analysis of randomized controlled trials. Am J Med. 2004;116:682-92.

32. Muller-Nordhorn J, Roll S, Willich SN. Comparison of the short form(SF)-12 health status instrument with the SF-36 in patients with coronary heart disease. Heart. 2004. doi:10.1136/hrt.2003.013995. Cardiovascular medicine.

\section{Submit your next manuscript to BioMed Central and take full advantage of:}

- Convenient online submission

- Thorough peer review

- No space constraints or color figure charges

- Immediate publication on acceptance

- Inclusion in PubMed, CAS, Scopus and Google Scholar

- Research which is freely available for redistribution 